\title{
The importance of expertise visibility across organizational boundaries for individual performance
}

\section{Keywords: expertise, transactive memory, knowledge, individual performance}

\begin{abstract}
The importance of knowledge sharing within engineering organizations is well acknowledged within the literature. A critical step to organizational knowledge sharing involves expertise visibility, or knowing who knows what, as employees must first identify who has the knowledge needed for project or organizational tasks before engaging in knowledge exchange. Thus, expertise visibility is theorized to improve group and organizational performance; however, there is a dearth of literature that has analyzed the importance of expertise visibility on employee performance. Due to the importance of employee performance for group and organizational performance, this research analyzed the relationship between expertise visibility and employee performance. Specifically, we analyzed responses to survey questionnaires to compare visibility across organizational boundaries with employee performance using social network analysis and linear regression analysis. Results showed that being visible across technical expertise, office, and hierarchy boundaries was associated with increased employee performance. Engineering organizations can use these results to encourage and incentivize employees to become more visible outside of their immediate groups in order to increase their performance. The paper contributes to theory of transactive memory by showing the importance of expertise visibility for performance at the individual level.
\end{abstract}

\section{Introduction}

In architecture, engineering and construction (AEC) organizations, an employee's performance is essential, as the aggregation of individual work directly turns into organizational outcomes. But, what 
influences employee performance? In the context of AEC organizations, scholars have suggested the importance of many individual skills, including communication and negotiating skills (Goodwin, 1993), leadership (Dainty, Cheng, \& Moore, 2003) and work experience (Krima, Wood, Aouad, \& Hatush, 2007). In this article, we argue that an employee's expertise, or knowledge and skill, is the most valuable resource, and, that the visibility of expertise across organizational boundaries allows for increased individual performance.

The importance of expertise visibility is explained by the knowledge-based theory of the firm, which argues that organizations and projects gain competitive advantage based on their ability to coordinate expertise (Grant, 1996). Nevertheless, a large portion of organizational expertise is invisible - as (Polanyi, 1967) famously stated "organizations know more than they can tell." Despite the concern that individual expertise is difficult to observe and make explicit, organizational literature continues to focus primarily on 'know-how' (knowledge) and 'know-what' (information) (Javernick-Will, 2013; Karlsen \& Gottschalk, 2004), with little research focusing on the importance of the 'know-who'. However, 'know who' is important for obtaining desired project and organizational outcomes, as these outcomes are not solely the effort of one individual, but instead require coordination of knowledge among a team of experts. As such, locating the right knowledge at the right time is often considered essential as it allows individuals to solve everyday engineering problems. The visibility of experts thus allows people to minimize time to locate the knowledge, reduce work duplication (Lapré \& Van Wassenhove, 2001) and enhance coordination (Hollingshead \& Brandon, 2003). As a result of these relationships, it is proposed that an individual's expertise visibility is associated with higher employee performance.

Previous research studying expertise visibility has focused on the importance of expertise visibility among members within project teams (Hollingshead \& Brandon, 2003). In large project-based organizations, such as AEC organizations, employees interact with others both within project and organizational 
boundaries. For instance, individuals who work in the same office may seek knowledge from each other even though they are assigned to work on distinct projects. Studying expertise visibility in the context of large AEC organizations is important because expertise becomes easily invisible due to the many organizational and geographic boundaries that separate individuals (Wanberg, Javernick-Will, Taylor, \& Chinowsky, 2012). Often these organizational boundaries will constrain visibility such that individuals will be more familiar with others in the same office or business units. As a result, solutions to problems may be reinvented in different parts of the organization, resulting in work inefficiencies. However, prior work has found that individuals who cross informal (Poleacovschi \& Javernick-Will, 2016) and organizational boundaries will benefit from their boundary-spanning positions (Burt, 2004; Cross \& Cummings, 2004; Cummings, 2004; Garstenauer, Blackburn, \& Olson, 2014; Poleacovschi \& JavernickWill, 2016), as crossing these boundaries allows individuals to gain access to new knowledge and skills (Alin, Taylor, \& Smeds, 2011). As such, we expect that expertise visibility across organizational boundaries will improve individual performance.

\section{Expertise visibility}

The concept of expertise visibility is rooted in transactive memory systems (TMS) theory. TMS traces back to Wegner (1991) who showed that individuals develop memory of what others know, referred to as transactive memory. According to TMS, individuals participate in collaborative work within their organizations and, through everyday interactions, develop understanding of others' expertise. The goal of the theory is to show that expertise in practice is embedded in social interactions, which help individuals develop awareness of others' expertise, store that information, and then use this information to approach experts when they need their knowledge. For example, a project manager develops memory about a construction worker's expertise by observing her work. The project manager may notice that the construction worker is skillful at welding, remember that information (awareness of her skills), and 
retrieve the knowledge that she is skilled at welding whenever needed. The information regarding her welding skills is developed through observation, problem solving, and remembering. The concept of expertise visibility, studied through the lenses of transactive memory, has primarily been studied at the group level (Hollingshead \& Brandon, 2003; Liang, Moreland, \& Argote, 1995). A group is believed to have high expertise visibility once individuals in the group are very familiar with each other. For example, expertise visibility would be minimal among two teams that are located in different countries, but would be expected to increase once they worked on a common project together.

Expertise visibility has gained increased interest in the literature due to its implications for project performance. Clear understanding of expertise among group members allows members to connect and coordinate work, which, in laboratory settings, has resulted in fewer project errors and shorter project completion time (Liang et al., 1995; Moreland \& Myaskovsky, 2000). Considering the benefits that can accrue from expertise visibility, scholars have been interested in identifying factors that can facilitate expertise visibility. Thus far, scholars have found that team learning (Liang et al., 1995) and communication (Hollingshead \& Brandon, 2003; Lewis, 2004) have increased expertise visibility. Within virtual AEC teams, a lack of group facilitators was found to enhance visibility by increasing individual interactions (Comu et al. 2013). However, while past research on expertise visibility has analyzed benefits at the group level, individual level benefits that accrue from having their expertise visible to others are unknown. Nevertheless, it is expected that the implications of expertise visibility on performance are similar to its impact on group level performance. For instance, previous research has shown that an individual who is highly visible in the organization is likely to become the subject matter expert providing knowledge to other parts of the group (Borgatti \& Cross, 2003). As a result, it is expected that they will be important contributors of knowledge to others within the group. 


\section{Boundary Work}

Large AEC organizations have accumulated a large amount of expertise resulting from the diverse experience developed, and knowledge gained, from working on different project types within different geographical regions. Taking full advantage of expertise is, however, disrupted by organizational boundaries. Typically the work within a department of a global engineering organization is divided among vertical boundaries (expertise), horizontal boundaries (hierarchy levels) and geographic boundaries (office location and country location). The goal of organizational boundaries is to use internal resources efficiently and to provide a sense of identity within the boundary (Santos \& Eisenhardt, 2005). Within a boundary, individuals create cohesive groups that homogenize and socialize based on common attributes. This idea is known as homophily, or love for the same, and is known to be a powerful predictor of the way individuals interact (McPherson, Smith-Lovin, \& Cook, 2001). Boundaries, however, are often considered to be harmful to the overall coordination of knowledge within the organization as they limit equal distribution of organizational resources. Indeed, previous research has shown that geographic boundaries disrupt knowledge sharing within AEC organizations as people tend to share knowledge with others in close proximity (Wanberg, Javernick-Will, Taylor, \& Chinowsky, 2015). Vertical boundaries also contribute to the formation of homophilic knowledge sharing connections in AEC; however the geographic ones have been identified to be more powerful (Wanberg, Javernick-Will, Chinowsky, \& Taylor, 2015). In other words, individuals in AEC organizations frequently interacted with similar experts and more frequently with individuals from the same geographic region. Finally, horizontal boundaries are known to be powerful predictor of employees' interactions as they establish the power dynamics within the organization. Nevertheless, despite the disruptive effects of boundaries on knowledge coordination, recent work proposes that organizational boundaries represent organizational opportunities (Landaeta, 2008) where learning and change takes place (Alin et al. 2011; Carlile 2002; Kerosou 2003). For instance, 
Alin et al. (2011) studied coordination of knowledge across organizational boundaries in the context of a project-based organizations. This previous research showed that the locus of knowledge transformation, or creation of new knowledge, is organizational boundaries.

Technical expertise boundaries separates people with different technical knowledge bases (e.g. engineer, designer). For instance, a telecommunications engineer has the knowledge on how to support and enhance the telecommunication systems while a project manager knows how to maintain project under desired schedule and cost. These experts' technical knowledge is essential for construction projects, as a large part of the work is technical in nature. A project becomes successful when the goals of all the experts engaged in the projects are being met. It was shown that project teams that collaborated effectively across their expertise boundary were likely to exhibit better project timing and performance in an experimental environment (Moreland \& Myaskovsky, 2000). These results emphasize the importance of expertise visibility across technical expertise boundaries. When individuals seek and exchange knowledge across their expertise boundary, they need to negotiate and translate their expertise to others who are different and may not have the same common understandings (Carlile 2004). Communicating their expertise and making it visible in different parts of the organization is not a linear process. Individuals learn about others' expertise based on their situated and ongoing interactions in which assessment takes place (Poleacovschi and Javernick-Will, 2016). Becoming visible, therefore, can be a lengthy process as the knowledge about know-who is deeply tacit and requires one-on-one interactions and contextual assessment (Dreyfus and Dreyfus 2005). Individuals who manage to translate their expertise across technical expertise boundaries develop communication skills that allow them to interact with external groups. In order to do so, they need to cultivate different meanings to cognitively comprehend expertise from across a technical expertise boundary (Carlile 2002). As a result, they become more knowledgeable of the expertise in diverse contexts and develop an expert's thinking (Dreyfus \& Dreyfus, 2005), or ability 
to use intuition when solving problems. This allows them to become problem solvers and apply their expertise quickly in different contexts - which has previously been shown to be the key to one's expertise level (Dreyfus \& Dreyfus, 2005). Considering these benefits, the following hypothesis is proposed:

Hypothesis 1: Individuals who are visible across their technical expertise boundary will have higher individual performance

Hierarchy level boundaries separate individuals in different levels. Accessing experts in different levels is known to positively contribute to individual performance (Cross \& Cummings, 2004). For instance, individuals in higher levels have the resources and social networks that can add to one's ability to find knowledge outside of their immediate networks. They will have more decision-making power and financial resources to implement those decisions. They will also have access to larger social networks and contacts within the organization that will help identify knowledge providers. Similarly, individuals in lower levels are resourceful due to their knowledge of a project context and specific details around project tasks. A person's visibility to those in different levels (both lower and higher levels) becomes important as individuals in higher and lower levels will share their knowledge with those they are familiar with (Borgatti \& Cross, 2003). As a result, visible individuals will gain new valuable knowledge. We propose the following hypothesis:

Hypothesis 2: Individuals who are visible across their hierarchy boundary will have higher individual performance

Geographic boundaries are especially applicable to large engineering organizations which continuously expand globally (Reina and Tulakz 2004). Project teams that share knowledge outside of their office location perform better (Cross \& Cummings, 2004; Cummings, 2004). An explanation for increased performance can be attributed to access to non-redundant knowledge outside of the office. People who 
work in the same office are familiar with one another and tend to assimilate over time based on similar work routines and local norms. The boundary (also known as structural holes) between two office locations allows for valuable knowledge to emerge based on accessing external cohesive groups (Burt, 1995). The origins of valuable knowledge comes from the non-redundancy of the knowledge gained from an external office. Once accessing one person in a new office location, the knowledge seeker gets relatively easy access to other contacts within that office due to the cohesive groups formed within an office. Individuals who are highly visible across geographic boundaries become the point of contact for external members. As such, the knowledge benefits that come from a boundary spanning role will positively affect their performance. Thus, we propose the following hypothesis:

Hypothesis 3: Individuals who are visible across their geographic boundaries (office location and country location) will have higher individual performance.

\section{Research Method}

To test these hypotheses, we collected and analyzed survey data from employees within the IT department of a large, multi-national infrastructure AEC organization. The organization specializes in water treatment projects, preconstruction, construction and construction management services and has operations in Europe, North America, South America, and Asia.

\section{Data collection}

The department includes 162 employees who are located in the US, UK, Middle East, and New Zealand. The department includes technical engineers and managers who provide IT services to the entire organization. A survey questionnaire was administered to employees within the department who provided data on: (1) expertise visibility and (2) individual attributes. A separate survey questionnaire asked managers to rate each employee's (3) individual performance. The response rate for the expertise visibility 
survey and individual attributes was $58 \%(n=94)$ while the response rate for employee performance was 74\% $(\mathrm{n}=118)$. We eliminated individuals who we did not have data from both the expertise visibility survey and their performance. Therefore, the final response rate for the analysis for all variables was $58 \%$ $(n=94)$.

\section{Dependent variable}

Data for the dependent variable, employee performance, were collected from each employee's immediate managers who rated their performance. Performance ratings were based on eight factors deemed important by the organization: knowledge and skills, business development, client service management, project management, general management, leadership, decision making and baseline skills. Project management and general management was excluded from the analyses because not everyone in the department was rated on these factors. Thus, six performance ratings were ultimately analyzed: knowledge and skills, business development, client service management, leadership, decision-making and baseline skills. In this article, we share results based on testing the relationships between expertise visibility and (1) each of the six individual performance ratings and (2) the average performance score of the six ratings. The average performance score gave equal weight to each of the six items measuring individual performance.

\section{Independent variables}

Questionnaires were distributed to all employees within the IT department to collect data on expertise visibility. Individuals were asked to assess their awareness of each employee's expertise within the department. They responded to the following statement:

"I understand this person's knowledge and skills. This does not necessarily mean that I have these skills or am knowledgeable in these areas, but that I understand what skills this person has and areas they are knowledgeable in." 
Their response options were based on a 6 - point scale (Blank- I do not know this person/I have never met this person; 1 - strongly disagree; 2 -disagree; 3 - somewhat disagree; 4 - somewhat agree; 5 -agree; 6 - strongly agree). For final data analysis, visible experts were individuals who received a score of 4 (somewhat agree), 5 (agree) and 6 (strongly agree).

To identify vertical boundaries (expertise), horizontal boundaries (hierarchy levels) and geographic boundaries (office location and country location) individuals were asked to identify their area of expertise, hierarchy level, country location and office location. Survey questions concerning technical expertise included: (1) Networks/Servers; (2) Messaging and Collaboration; (3) Application Support/Development; (4) End User Support; (5) Field Operations; (6) Telecommunications; (7) Project Management; (8) Asset Management/Standards; (9) Security; (10) Training; (11) Business Support. Survey questions concerning hierarchy asked to identify their hierarchy level from the following levels: 1 -individual contributor/team member; 2 -supervisor/team leader; 3 - project manager/program manager; 4 - manager/BU [business unit] manager; 5 -director). Office location included a total of eleven offices in several countries and world regions. Five offices were located in the US, two in the UK, one in New Zealand, one in India, and two in Middle East and Asia-Pacific. Finally, we controlled for levels of tenure and gender in all the models. Tenure included the number of years individuals worked for the company, and gender was a dichotomous variable.

Data were cleaned and analyzed using social network analysis in Netminer. The visibility score across organizational boundaries was calculated using the homophily in-neighbors command in Netminer, which allowed us to calculate the number of connections an individual has outside of a particular attribute boundary (e.g. expertise). We created four variables - visibility across expertise boundary (boundary_expertise), visibility across country boundary (boundary_country), visibility across office boundary (boundary_office), and visibility across hierarchy boundary (boundary_hierarchy). For instance, 
if a telecommunications worker's expertise is visible to five project managers, it means that he or she would cross the expertise boundary five times, resulting in a score of five on their visibility across technical expertise boundary score (boundary_expertise).

\section{Results}

Tenure and gender were included as control variables. The average tenure for the respondent was six years. The sample included 33 women respondents (33\% of the sample) and 61 men respondents $(67 \%$ of the sample). Exhibit 1 shows the pairwise relationships between all variables in the model. The correlations represent a preliminary analysis into our hypotheses evaluating the relationship between expertise visibility across four boundaries and individual performance. As shown in Exhibit 1, the individual performance score is correlated with boundary_expertise, boundary_hierarchy, and boundary_office, offering preliminary evidence that expertise visibility may influence individual performance. Further statistical analysis is done to validate the relationship.

\section{*Insert Exhibit 1 here*}

Linear regression analysis in Exhibit 2 shows the relationship between visibility across boundary scores and individual performance. The numbers without parenthesis represent regression coefficients while the numbers in parenthesis represent standard errors. Model 1 examined the relationship between visibility across four boundaries and individual performance. The model was included to identify whether a particular boundary plays a more important role for employee performance ratings by holding visibility across the four boundaries constant. As Model 1 shows, technical expertise visibility across expertise boundary is the only variable that is significant. A one-unit increase in boundary expertise score was associated with a .01 unit increase in individual performance. To validate the results in Model 1, the stepwise backward elimination method was performed. The method eliminates the variables that are the 
least significant one step at a time (Meyers, Gamst, \& Guarino, 2006). The model identified variables that are significant and best predict the outcome variable. Model 2 presents the results from the backward elimination and shows a positive and highly significant relationship $(\mathrm{p}<0.001)$. The results in Model 2 validate the importance of visibility across expertise boundary for individual performance and validate hypothesis 1 . To test assumptions for the linear regression analysis, we performed the Shapiro-Wilk normality test of residuals. The p-value for the test was higher than 0.05 showing the normality of residuals.

\section{*Insert Exhibit 2 here*}

The second set of results (Exhibits 3-6) show relationships between expertise visibility across the four boundaries - expertise, hierarchy, office and country — and the six items measuring performanceknowledge and skills, business development, client service management, leadership, decision making and baseline skills - using linear regression analysis. The numbers without parentheses represent regression coefficients, while the numbers in parentheses represent standard errors. The dependent variable, performance, was measured on a scale from 0 to 5 .

Exhibit 3 analyzes the relationship between expertise visibility across technical expertise boundaries and individual performance ratings. The exhibit includes six models based on the six performance ratings. The results in the exhibit show that an increase in expertise visibility across expertise boundary in all models is associated with individual performance ratings (positive coefficient and $\mathrm{p}<0.01$ ). The results validate Hypothesis 1 stating that expertise visibility across expertise boundary is associated with individual performance.

*Insert Exhibit 3 here* 
Exhibit 4 analyzes the relationship between expertise visibility across hierarchy boundaries and individual performance ratings. The exhibit includes six models based on the six performance ratings. The results in the exhibit show that an increase in expertise visibility across hierarchy boundary in all models is associated with individual performance ratings (positive coefficient and $p<0.05$ ). The results validate Hypothesis 2 stating that expertise visibility across hierarchy boundary is associated with increase in individual performance.

\section{*Insert Exhibit 4 here*}

Exhibit 5 analyzes the relationship between expertise visibility across office boundaries and individual performance ratings. The exhibit includes six models based on the six performance ratings. The results in the exhibit show that an increase in expertise visibility across office boundary in all models is associated with individual performance ratings (positive coefficient and $\mathrm{p}<0.05$ ). The results validate Hypothesis 3, stating that expertise visibility across office boundary is associated with an increase in all individual performance ratings, except business development.

\section{*Insert Exhibit 5 here*}

Finally, Exhibit 6 analyzes the relationship between expertise visibility across country boundary and individual performance ratings. The exhibit includes six models based on the six performance ratings. The results in the exhibit show that an increase in expertise visibility across country boundary in all models was not associated with individual performance ratings (negative coefficient and $\mathrm{p}>0.05$ ). The results do not support Hypothesis 3 stating that expertise visibility across country boundary is associated with an increase in individual performance.

\footnotetext{
*Insert Exhibit 6 here*
}

\section{Discussion}


This research evaluated the importance of expertise visibility outside of one's immediate organizational boundaries. While previous work has shown that crossing informal boundaries is associated with individual performance (Poleacovschi \& Javernick-Will, 2016), it is not known whether formal organizational boundaries play a similar role. Using linear regression analyses, we found a significant and positive relationship between expertise visibility across vertical and horizontal organizational boundaries and individual performance ratings. Specifically, individuals whose expertise was visible across their expertise, hierarchy, and office boundaries were likely to have increased individual performance (Exhibit 2). The highest effect was found for the relationship between expertise visibility across hierarchy boundary and individual performance.

Crossing office boundary was associated with increased individual performance. An individual may become visible across office boundaries once they have spent time working on projects located in different offices or if they make themselves visible across these boundaries by participating in organizational activities (e.g. online communities of practice). From a knowledge perspective, individuals who are located in the same office tend to assimilate and have similar knowledge bases, which may explain the decrease in performance. Conversely, individuals who have the ability to reach across these boundaries will have an advantage due to accessing non-overlapping and innovative knowledge (Burt, 2004; Granovetter, 1973). Contrary to our hypothesis, crossing country boundary was not associated with increased individual performance. An explanation for this can be the fact that engineering knowledge is cultural and context dependent. For instance, engineers use specific codes that operate at the country level in their everyday work. As such, it is possible that individuals who cross country boundaries do not necessarily benefit, as the knowledge obtained may be less applicable to their context. Crossing hierarchical boundaries was also associated with increased performance. This means that individuals who manage to be visible to others at different hierarchy levels were likely to be rated as high performers. 
Bridging hierarchical levels can be important as levels act as "thick" barriers in knowledge sharing due to differences in power relationships (Michailova \& Husted, 2003). As such, individuals who manage to cross hierarchy boundaries have access to different sets of knowledge and also balance the power relationships in the organization. This means that these hierarchy crossing individuals can act as problem solvers in both knowledge-based problems and potentially social problems, such as communication gaps. Finally, the relationship between expertise visibility across technical expertise boundary was positive and significant. In other words, whenever an engineer makes himself or herself visible to a group of individuals with different expertise, such as a security engineer or a project manager, this may positively influence individual performance. The relationship can also be explained by the fact that individuals who seek knowledge from other type of experts learn new knowledge and skills that allow them to employ knowledge that differs from their peers, who primarily seek knowledge within their homophily group. When including expertise visibility across the four boundaries in one model (Exhibit 2), we found that visibility across boundaries of technical expertise was the only variable that remained significant, which validated its importance for individual performance. One explanation for these results is that individuals who are visible across these boundaries possess, or have access to, non-redundant expertise, which increases their value to the group and thus impacts their performance ratings.

This research adds to the transactive memory literature by showing that expertise visibility matters for individual performance. In previous research, expertise visibility at the group level was analyzed with group performance (Comu et al. 2013). In a similar manner, we showed that individuals were likely to be rated higher whenever more members within the department were aware of their expertise. This implies that the organization —at least managers within an organization—rated the performance of individuals higher when individual expertise was more visible to others. Previous research has shown that individuals tend to interact and share knowledge amongst similar others (Wanberg, Javernick-Will, Taylor, et al., 
2015); however we have shown that expertise visibility beyond one's immediate group is associated with individual performance ratings. Thus, we have identified an important phenomena that requires further attention from both engineering practitioners and researchers.

\section{Managerial Implications}

This research has important managerial implications. Employees who become visible across organizational boundaries likely manage to do so by directly engaging in project work with people in different parts of the organization, by helping others when approached, or by simply marketing their expertise. Because they span the formal boundaries of the organization, they become central points of contact for others in the organization based upon their expertise and knowledge of who knows what. These boundary spanners are particularly helpful for engineering organizations with employees who work on unique projects in different parts of the organization and globe. This project-based environment creates subgroups with unique knowledge that boundary spanners are able to access and transfer across boundaries. Because boundary spanning capabilities are valuable to the organization, managers can encourage employees to develop these capabilities. First, managers can emphasize and explain the value of becoming visible outside of their immediate formal boundary, both to the organization and, based upon this research, to their employees. Second, managers can encourage boundary-spanning behavior by purposefully pairing individuals from different subgroups or organizational units to work together on a project. They can encourage them to highlight their expertise so that it is known and recognized outside of their organizational unit. They can also consider rewarding, either through social recognition or financial incentives, employees who participate in events and foster connections outside of their formal boundaries. By helping employees recognize and develop these boundary-spanning connections, 
employees should be able to create connections outside of their formal networks, which can provide valuable, non-redundant knowledge to their unit.

\section{Limitations and future work}

As with any research, the results presented in this article have several limitations. First, employee performance was assessed by managers, which represents managers' perception of performance and may not reflect actual performance. Second, this research was conducted within a single department of one organization and thus cannot be generalized across all departments or across other organizations. It can be expected that data can be generalized to other companies with similar characteristics to the organization studied. For example, performance based on visibility across expertise boundaries has importance in AEC companies where people solve ill-structured problems and coordination of non-redundant expertise is essential for achieving everyday engineering tasks. Thus, future research should test this model across additional cases and organizations. Finally, a possible explanation for the observed results is that the dependent variable (employee performance) actually explained the independent variables (expertise visibility), which means that when an individual receives higher performance ratings, others become aware of their expertise which explains high visibility scores. Future research must validate these potential explanations, which would require additional qualitative or longitudinal data and analysis alternate.

\section{Conclusions}

Many AEC organizations seek to increase knowledge sharing amongst employees to help solve problems and complete project- and organizational- related tasks. However, in order to seek and provide knowledge from and to colleagues, employees must be aware of other's knowledge. We tested whether expertise visibility is associated with individual performance within the IT department of a multinational infrastructure engineering organization. Using average performance ratings by managers, we found that an individual's expertise visibility across vertical boundaries (expertise), horizontal boundaries (hierarchy 
levels) and geographic boundaries (office location and country location) was associated with individual performance. These findings expand transactive memory theory by showing that visibility has implications for individual performance. In practice, AEC practitioners can encourage and incentivize employees to increase the visibility of their knowledge across their office, country and hierarchy boundaries, citing the correlation between awareness and performance ratings.

\section{References}

Alin, P., Taylor, J. E., \& Smeds, R. (2011). Knowledge transformation in project networks: A speech act level cross-boundary analysis. Project Management Journal, 42(4), 58-75. https://doi.org/10.1002/pmj.20254

Borgatti, S. P., \& Cross, R. (2003). A Relational View of Information Seeking and Learning in Social Networks. Management Science, 49(4), 432-445. https://doi.org/10.1287/mnsc.49.4.432.14428

Burt, R. (1995). Structural Holes: The Social Structure of Competition. Cambridge, Mass.: Harvard University Press.

Burt, R. S. (2004). Structural Holes and Good Ideas. American Journal of Sociology, 110(2), 349-399. https://doi.org/10.1086/421787

Carlile, P. (2002). A Pragmatic View of Knowledge and Boundaries: Boundary Objects in New Product Development. Organization Science, 13(4), 442-455. https://doi.org/10.1287/orsc.13.4.442.2953

Cross, R., \& Cummings, J. N. (2004). Tie and Network Correlates of Individual Performance in Knowledge-Intensive Work. The Academy of Management Journal, 47(6), 928-937. https://doi.org/10.2307/20159632

Cummings, J. N. (2004). Work Groups, Structural Diversity, and Knowledge Sharing in a Global Organization. Management Science, 50(3), 352-364. https://doi.org/10.1287/mnsc.1030.0134 
Dainty, A. R. J., Cheng, M.-I., \& Moore, D. R. (2003). Redefining performance measures for construction project managers: an empirical evaluation. Construction Management and Economics, 21(2), 209-218. https://doi.org/10.1080/0144619032000049737

Dreyfus, H. L., \& Dreyfus, S. E. (2005). Peripheral Vision Expertise in Real World Contexts. Organization Studies, 26(5), 779-792. https://doi.org/10.1177/0170840605053102

Garstenauer, A., Blackburn, T., \& Olson, B. (2014). A Knowledge Management Based Approach to Quality Management for Large Manufacturing Organizations. Engineering Management Journal: EMJ; Huntsville, 26(4), 47-58.

Goodwin, R. (1993). Skills Required of Effective Project Managers. Journal of Management in Engineering, 9(3), 217-226. https://doi.org/10.1061/(ASCE)9742-597X(1993)9:3(217)

Granovetter, M. S. (1973). The Strength of Weak Ties. American Journal of Sociology, 78(6), 13601380.

Grant, R. M. (1996). Toward a knowledge-based theory of the firm. Strategic Management Journal, 17(S2), 109-122. https://doi.org/10.1002/smj.4250171110

Hollingshead, A. B., \& Brandon, D. P. (2003). Potential Benefits of Communication in Transactive Memory Systems. Human Communication Research, 29(4), 607-615. https://doi.org/10.1111/j.1468-2958.2003.tb00859.x

Javernick-Will, A. (2013). Local Embeddedness and Knowledge Management Strategies for ProjectBased Multi-National Firms. Engineering Management Journal; EMJ, 25(3), 16-26.

Karlsen, J. T., \& Gottschalk, P. (2004). Factors Affecting Knowledge Transfer in IT Projects. Engineering Management Journal, 16(1), 3-11. https://doi.org/10.1080/10429247.2004.11415233 
Krima, N. A., Wood, G., Aouad, G. F., \& Hatush, Z. (2007). Assessing the performance of Libyan supervising engineers. Construction Management and Economics, 25(5), 509-518. https://doi.org/10.1080/01446190701247883

Landaeta, R. E. (2008). Evaluating Benefits and Challenges of Knowledge Transfer Across Projects. Engineering Management Journal, 20(1), 29-38.

Lapré, M. A., \& Van Wassenhove, L. N. (2001). Creating and Transferring Knowledge for Productivity Improvement in Factories. Management Science, 47(10), 1311-1325. https://doi.org/10.1287/mnsc.47.10.1311.10264

Lewis, K. (2004). Knowledge and Performance in Knowledge-Worker Teams: A Longitudinal Study of Transactive Memory Systems. Management Science, 50(11), 1519-1533. https://doi.org/10.1287/mnsc.1040.0257

Liang, D. W., Moreland, R., \& Argote, L. (1995). Group Versus Individual Training and Group Performance: The Mediating Role of Transactive Memory. Personality and Social Psychology Bulletin, 21(4), 384-393. https://doi.org/10.1177/0146167295214009

McPherson, M., Smith-Lovin, L., \& Cook, J. M. (2001). Birds of a Feather: Homophily in Social Networks. Annual Review of Sociology, 27, 415-444.

Meyers, L. S., Gamst, G., \& Guarino, A. J. (2006). Applied Multivariate Research: Design and Interpretation. SAGE.

Michailova, S., \& Husted, K. (2003). Knowledge-Sharing Hostility in Russian Firms. California Management Review, 45(3), 59.

Moreland, R. L., \& Myaskovsky, L. (2000). Exploring the Performance Benefits of Group Training: Transactive Memory or Improved Communication? Organizational Behavior and Human Decision Processes, 82(1), 117-133. https://doi.org/10.1006/obhd.2000.2891 
Polanyi, M. (1967). The Tacit Dimension. London, Routledge \& K. Paul.

Poleacovschi, C., \& Javernick-Will, A. (2016). Spanning information and knowledge across subrgoups and its effects on individual performance. Journal of Management in Engineering.

Santos, F. M., \& Eisenhardt, K. M. (2005). Organizational Boundaries and Theories of Organization. Organization Science, 16(5), 491-508. https://doi.org/10.1287/orsc.1050.0152

Wanberg, J., Javernick-Will, A., Chinowsky, P., \& Taylor, J. (2015). Spanning Cultural and Geographic Barriers with Knowledge Pipelines in Multinational Communities of Practice. Journal of Construction Engineering and Management, 141(4), 04014091. https://doi.org/10.1061/(ASCE)CO.1943-7862.0000955

Wanberg, J., Javernick-Will, A., Taylor, J., \& Chinowsky, P. (2012). Knowledge Sharing Networks in Multi-National Communities of Practice: fragmentation, pipelines and anomalies. Journal of Construction Engineering and Management (Revision under Review).

Wanberg, J., Javernick-Will, A., Taylor, J. E., \& Chinowsky, P. (2015). The effects of organizational divisions on knowledge-sharing networks in multi-lateral communities of practice. Engineering Project Organization Journal, 5(2-3), 118-132. https://doi.org/10.1080/21573727.2015.1059823 
